\title{
High Temperature Erosion Wear of Cermet Particles Reinforced Self-Fluxing Alloy HVOF Sprayed Coatings
}

\section{Andrei SURZHENKOV ${ }^{1}$, Dmitri GOLJANDIN ${ }^{2}$, Rainer TRAKSMAA ${ }^{2}$, Mart VILJUS ${ }^{2}$, Kristofer TALVISTE ${ }^{3}$, Aare ARUNIIT ${ }^{1}$, Jyrki LATOKARTANO ${ }^{4}$, Priit KULU $^{2}$}

\author{
${ }^{1}$ Department of Materials Engineering, Tallinn University of Technology, Ehitajate tee 5, 19086 Tallinn, Estonia \\ ${ }^{2}$ Centre for Materials Research, Tallinn University of Technology, Ehitajate tee 5, 19086 Tallinn, Estonia \\ ${ }^{3}$ Paide Machine Factory, Tööstuse 7, 72720 Paide, Estonia \\ ${ }^{4}$ Mechanical Engineering and Industrial Systems Unit, Tampere University of Technology, Korkeakoulunkatu 10, \\ FI-33720 Tampere, Finland
}

crossref http://dx.doi.org/10.5755/j01.ms.21.3.7617

\section{Received 17 July 2014; accepted 25 December 2014}

\begin{abstract}
The resistance of high velocity oxy-fuel (HVOF) sprayed TiC-NiMo and $\mathrm{Cr}_{3} \mathrm{C}_{2}$-Ni cermet particles reinforced $\mathrm{NiCrSiB}$ self-fluxing alloy coatings to high temperature erosion wear was studied. Microstructure of the coatings was examined by SEM, phase composition was determined by XRD. A four-channel centrifugal particle accelerator was applied to study the high temperature erosion wear of the coatings. The angles of impingement were $30^{\circ}$ and $90^{\circ}$, initial particle velocity was $50 \mathrm{~m} / \mathrm{s}$, the average temperature of the test $-650^{\circ} \mathrm{C}$. Volume wear of the coatings was calculated and compared to the respective values of the reference materials. Wear mechanisms were studied by SEM. HVOF sprayed coatings exhibited lower wear, than WC-15Co hardmetal and steel HARDOX 400, but higher wear than steel AISI 304. TiC-NiMo particles reinforced self-fluxing alloy coating demonstrated virtually the same wear resistance, as the $\mathrm{Cr}_{3} \mathrm{C}_{2}-\mathrm{Ni}$ particles reinforced self-fluxing alloy coating, at $30^{\circ}$ and the better wear resistance at $90^{\circ}$.

Keywords: self-fluxing alloy, cermet, HVOF spraying, composite coating, high temperature wear, erosion wear.
\end{abstract}

\section{INTRODUCTION}

The usage of Ni-based alloys is widely established there, where a good resistance to oxidation and wear [1] both at moderate and elevated temperatures [2-7] is required. Among the other, $\mathrm{NiCrSiB}$ self-fluxing alloys (SFA) stand out for the comparably better mechanical and technological properties. The additions of silicon and boron increase the self-fluxing capability of these alloys, thus enhancing the opportunities to produce coatings from them. In addition to that, the presence of boron lowers the melting point of a NiCrSiB alloy, and the broad solidification range makes it easier to manufacture coatings by thermal spraying [8].

However, in some cases the SFAs alone can't provide the required wear resistance. To solve this problem, a co-deposition of a NiCrSiB alloy and a hard phase, mostly a tungsten carbide-based material, is usually attempted. It has been shown that coatings of such a composition demonstrate lower wear due to the combination of the relative toughness of the SFA and the hardness of the hardmetal [9-11]. In their turn, TiC- and $\mathrm{Cr}_{3} \mathrm{C}_{2}$-based cermets proved to be suitable alternatives for the WC-based hardmetals due to their high wear and corrosion/oxidation resistance, especially at elevated temperatures [12-17]. It was formerly shown that the application of the TiC-NiMo and $\mathrm{Cr}_{3} \mathrm{C}_{2}$-Ni cermets as a reinforcement in the high velocity oxy-fuel sprayed (HVOFS) NiCrSiB coatings allowed to increase their

\footnotetext{
${ }^{*}$ Corresponding author. Tel.: +372-620-3379; fax: +372-620-3196. E-mail address: andrei.surzenkov@ttu.ee (A. Surzhenkov)
}

resistance to abrasive wear by up to 1.6 times at the room temperature in comparison with the unreinforced coating [18]. Analogously, the composite $\mathrm{NiCrSiB} / \mathrm{Cr}_{3} \mathrm{C}_{2}-\mathrm{Ni}$ HVOFS coating demonstrated 1.6 times lower abrasive wear than the steel C45 at the room temperature [19]. Still, to authors' best knowledge, no research concerning the high temperature wear of a $\mathrm{TiC}$ - or $\mathrm{Cr}_{3} \mathrm{C}_{2}$-based cermet particles reinforced thermal sprayed coating with a SFA matrix has been conducted yet. In the present paper, authors concentrate on the high temperature erosion wear of the TiC-NiMo and $\mathrm{Cr}_{3} \mathrm{C}_{2}-\mathrm{Ni}$ particles reinforced HVOFS coatings with the NiCrSiB matrix and compare the wear values to the other widespread wear resistant materials (steels AISI 304 and HARDOX 400 and WC-15Co hardmetal).

\section{EXPERIMENTAL}

\subsection{Preparation of coatings by HVOFS}

The coatings were sprayed onto flat samples (size $50 \times 25 \times 10 \mathrm{~mm}$ ), machined from carbon steel C45 and grit blasted prior to spraying (abrasive media $-\mathrm{Al}_{2} \mathrm{O}_{3}$; final roughness $R \mathrm{a}=10.0 \pm 1.0 \mu \mathrm{m})$. The kerosene fuelled Tafa JP-5000 (Praxair Inc.) HVOFS device was applied for spraying of the coatings. The process parameters are given in Table 1. Fusion of the HVOFS coatings was found unnecessary, as they exhibited a similar wear resistance to that of the sprayed and fused coatings [2]. The initial sprayed powders were the mixtures of commercial NiCrSiB SFA powder and experimental cermet powder (weight proportion $3: 1$ ). The detailed information about the used powders is given in Table 2 . 
Table 1. Parameters of the HVOF spraying process

\begin{tabular}{|c|c|}
\hline Parameter & Value \\
\hline Oxygen supply pressure & $1.45 \mathrm{MPa}$ \\
\hline Oxygen flow pressure & $0.97 \mathrm{MPa}$ \\
\hline Oxygen flow & $1.53 \times 10^{-2} \mathrm{~m}^{3} / \mathrm{s}$ \\
\hline Kerosene supply pressure & $1.17 \mathrm{MPa}$ \\
\hline Kerosene work pressure & $0.83 \mathrm{MPa}$ \\
\hline Kerosene flow & $5.56 \times 10^{-6} \mathrm{~m}^{3} / \mathrm{s}$ \\
\hline Combustion pressure & $0.71 \mathrm{MPa}$ \\
\hline Nitrogen pressure & $0.50 \mathrm{MPa}$ \\
\hline Nitrogen flow & $4.50 \times 10^{-4} \mathrm{~m}^{3} / \mathrm{s}$ \\
\hline Spraying distance & $0.38 \mathrm{~m}$ \\
\hline
\end{tabular}

Table 2. Parameters of the sprayed powders

\begin{tabular}{|c|c|c|}
\hline Powder & Chemical composition, wt.\% & $\begin{array}{c}\text { Particle size } \\
\text { range, } \mu \mathrm{m}\end{array}$ \\
\hline $\begin{array}{c}\text { NiCrSiB } \\
\mathrm{SFA}^{1)}\end{array}$ & $\begin{array}{c}7.35 \mathrm{Cr}, 2.16 \mathrm{Fe}, 0.25 \mathrm{C}, \\
3.52 \mathrm{Si}, 1.72 \mathrm{~B}, 0.032 \mathrm{O}, \mathrm{bal} . \mathrm{Ni}\end{array}$ & $+20-53$ \\
\hline $\begin{array}{c}\mathrm{TiC}^{-} \\
\mathrm{NiMo}^{2)}\end{array}$ & $70 \mathrm{TiC}, 20 \mathrm{Ni}, 10 \mathrm{Mo}$ & $+20-63$ \\
\hline $\mathrm{Cr}_{3} \mathrm{C}_{2}-\mathrm{Ni}^{2)}$ & $70 \mathrm{Cr}_{3} \mathrm{C} 2,30 \mathrm{Ni}$ & $+20-63$ \\
\hline $\begin{array}{l}\text { 1) } 1640-02 \text { (Höganäs } \mathrm{AB}) \\
\text { 2) } \\
\text { disintegrator milled (Tallinn University of Technology) }\end{array}$ \\
\hline
\end{tabular}

\subsection{Microstructure studies}

The microstructure of the HVOFS coatings was studied, applying the scanning electron microscope (SEM) EVO MA-15 (Carl Zeiss), equipped with the energy dispersive spectroscopy (EDS) device. The actual matrix / reinforcement proportion in the sprayed coatings was calculated by the SEM images according to the ASTM E112-10 standard. The obtained data was used to calculate the actual density of the coatings. The phase composition of the coatings was determined by the X-ray diffraction (XRD) method applying AXS 5005 diffractometer, equipped with $\mathrm{Cu} \mathrm{K}_{\alpha}$ radiation source (Bruker).

\subsection{High temperature erosion test}

For the high temperature erosion tests, the fourchannel centrifugal particle accelerator [17] was applied. $\mathrm{SiO}_{2}$ quartz sand (particle size $0.1-0.3 \mathrm{~mm}$ ) was used as the abrasive, its total weight was $6 \mathrm{~kg}$. The particle velocity was $50 \mathrm{~m} / \mathrm{s}$, the testing temperature was $650{ }^{\circ} \mathrm{C}$ and the angles of impingement were $30^{\circ}$ and $90^{\circ}$. The whole testing process lasted $2 \mathrm{~h} 15 \mathrm{~min}$ (1 h $30 \mathrm{~min}$ for reaching the required temperature and $45 \mathrm{~min}$ - the erosion wear test itself). The commercial steels AISI 304 (EN X5CrNi18-10) and HARDOX 400, as well as the WC-15Co hardmetal, produced at Tallinn University of Technology, were used as the reference materials. Specimens were cleaned in acetone and weighed before and after the test.

To estimate the influence of the oxidation of the substrate of the specimens, after the erosion test their back surfaces were reground to remove the oxides, following by weighing and heating in the furnace at the identical temperature and time conditions, as during the test. After that the specimens were weighed again. The average weight gain due to the oxidation of the back surfaces equalled to $3.3 \mathrm{mg}$ in the case of the WC-15Co hardmetal, $1.5 \mathrm{mg}$ in the case of steel HARDOX 400 and $1.9 \mathrm{mg}$ in the case of the substrate steel C45. The steel AISI 304 exhibited the average wear loss of $0.1 \mathrm{mg}$.

Taking into account this deduction, the average volumetric wear loss of the coatings and the reference materials was calculated by the following equation:

$$
V=\frac{m}{\rho},
$$

where $V$ is the volumetric wear loss, $\mathrm{mm}^{3} ; m$ is the average weight loss, mg; $\rho$ is the density of the coating (steel, hardmetal).

\section{RESULTS AND DISCUSSION}

\subsection{Microstructure studies}

The HVOFS coatings exhibit a dense structure with a negligible amount of defects (Fig. 1). The contents of the reinforcing phase (TiC-NiMo or $\mathrm{Cr}_{3} \mathrm{C}_{2}-\mathrm{Ni}$ ) in the coatings were remarkably lower in comparison with the initial powder mixtures. The actual content of the $\mathrm{Cr}_{3} \mathrm{C}_{2}-\mathrm{Ni}$ particles was around $20 \mathrm{wt} \%$ and of the TiC-NiMo particles - only about 6.5 wt.\% in the respective coatings. A lower content of the cermet phase in the HVOFS coatings than in the initial powders can be explained by the differences in the densities of the SFA alloy and the reinforcement. The density of the sprayed $\mathrm{NiCrSiB}$ alloy is approximately $8.4 \mathrm{~g} / \mathrm{cm}^{3}$, the densities of the TiC-NiMo and the $\mathrm{Cr}_{3} \mathrm{C}_{2}$-Ni cermets -5.8 and $7.2 \mathrm{~g} / \mathrm{cm}^{3}$, respectively [20]. During the spraying process, heavier particles will knock material with a lower weight out of the coating at the account of a higher kinetic energy [21]. The bigger is the difference in the weight, the higher loss of less dense particles will occur. Bearing in mind the comparable particle size of the SFA and the cermet powders, the loss of the cermet phase should have taken place, what is in accordance with the microstructure observations.

As it follows from Fig. 2, the studied HVOFS coatings have complicated phase compositions. The XRD analysis has shown the presence of different Ni compounds, such as $\mathrm{Ni}_{3} \mathrm{~B}, \mathrm{NiSi}$ and $\mathrm{Ni}_{3} \mathrm{Fe}$, as well as chromium boride $\mathrm{CrB}$, which are commonly found in $\mathrm{NiCrSiB}$ hardfacings [22-24], as well as phases, typical for cermets (TiC, $\mathrm{Cr}_{3} \mathrm{C}_{2}, \mathrm{Cr}_{7} \mathrm{C}_{3}, \mathrm{Cr}_{23} \mathrm{C}_{6}$ ). In addition to them, some complicated phases $\left(\mathrm{Cr}_{0.31} \mathrm{Mo}_{0.07} \mathrm{Mn}_{0.02} \mathrm{Fe}_{0.52}\right.$ and $\mathrm{TiMnSi}_{2}$ in the TiC-NiMo particles reinforced coating and $\mathrm{Cr}_{21.34} \mathrm{Fe}_{1.66} \mathrm{C}_{6}$ in the $\mathrm{Cr}_{3} \mathrm{C}_{2}-\mathrm{Ni}$ particles reinforced one), which appeared most probably as a result of the reaction between the SFA matrix and reinforcement components, were discovered; however, their amount was negligible. This is in a good correspondence with the previous results $[18,19,25]$, where absent or minor dissolution of the cermet and/or hardmetal phase in the SFA matrix was reported.

It is also interesting to note that a Fe-Cr solid solution was detected in the TiC-NiMo particles reinforced coating, whereas no traces of it could be found in the $\mathrm{Cr}_{3} \mathrm{C}_{2}-\mathrm{Ni}$ particles reinforced one. 


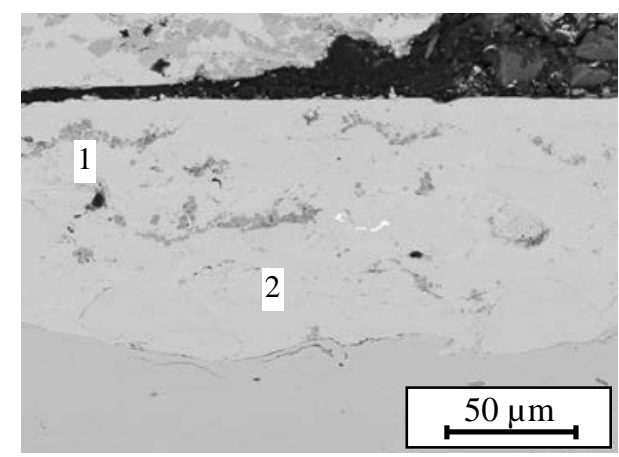

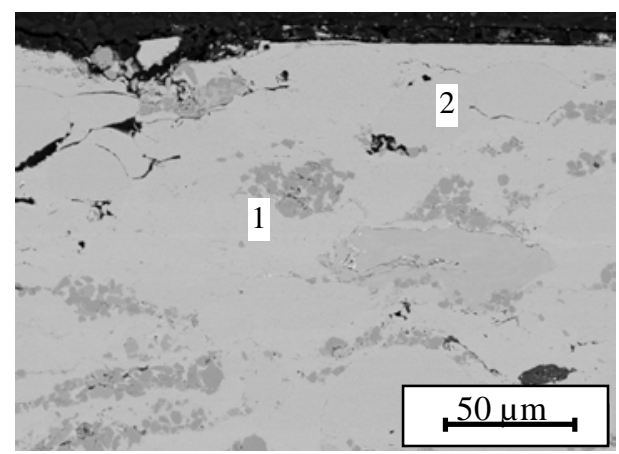

b

Fig. 1. Microstructures of the HVOFS coatings: a $-\mathrm{NiCrSiB}+\mathrm{TiC}-\mathrm{NiMo} ; \mathrm{b}-\mathrm{NiCrSiB}+\mathrm{Cr}_{3} \mathrm{C}_{2}-\mathrm{Ni} ; 1-$ cermet phase; $2-\mathrm{NiCrSiB}$ phase

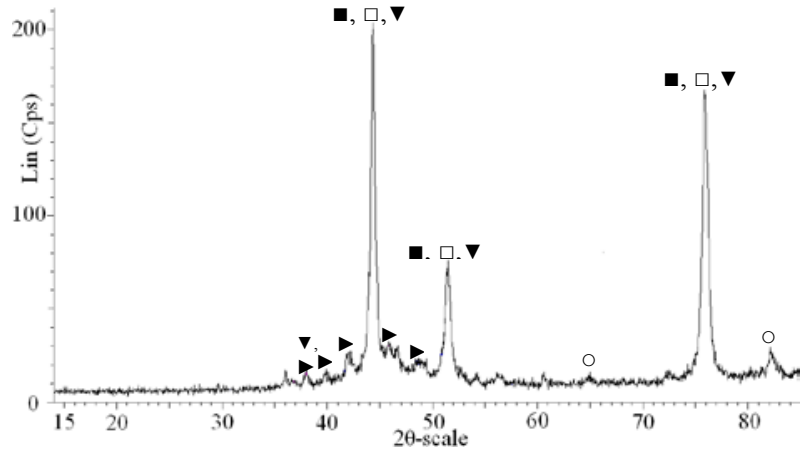

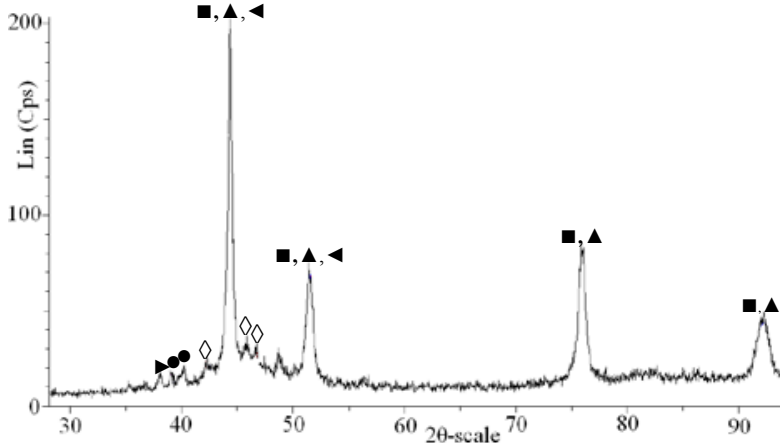

b

Fig. 2. XRD patterns of the HVOFS coatings: a $-\mathrm{NiCrSiB}+\mathrm{TiC}-\mathrm{NiMo}$; $-\mathrm{NiCrSiB}+\mathrm{Cr}_{3} \mathrm{C}_{2}-\mathrm{Ni} ; \mathbf{\nabla}-\mathrm{Fe}_{23} \mathrm{~B}{ }_{2} \mathrm{C} 4 ;--\mathrm{Ni} 3 \mathrm{~B}$; $\mathbf{a}-\mathrm{Ni} 3 \mathrm{Fe}$;

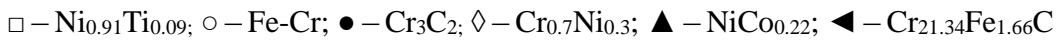

This could be explained by a lower reinforcement content in the first coating and, consequently, a lower total carbon content.

\subsection{High temperature erosion wear}

At the low angle of impingement $\left(30^{\circ}\right)$ both TiC-NiMo and $\mathrm{Cr}_{3} \mathrm{C}_{2}-\mathrm{Ni}$ particles reinforced coatings showed 1.3 times lower wear in comparison with the WC-15Co hardmetal and 1.5 times lower wear in comparison with steel HARDOX 400 (Fig. 3). In contrast with that, both HVOFS coatings exhibited approximately 2.4 times higher wear than steel AISI 304.

At the normal angle of impingement $\left(90^{\circ}\right)$, the TiC-NiMo particles reinforced coating demonstrated 3 and 5.3 times lower wear, than the WC-15Co hardmetal and steel HARDOX 400, respectively. Correspondent relative wear values for the $\mathrm{Cr}_{3} \mathrm{C}_{2}-\mathrm{Ni}$ particles reinforced coating were 1.8 and 3.3. However, at the normal angle of impingement the wear of steel AISI 304 was 1.7 times smaller to compare with the TiC-NiMo particles reinforced HVOFS coating and 2.7 times less to compare with $\mathrm{Cr}_{3} \mathrm{C}_{2}$-Ni particles reinforced one (Fig. 3).

The principle wear mechanism of both studied HVOFS coatings at the low angle of impingement was microcutting (Fig. 4 a, b) [26].

It was less intensive in the case of the $\mathrm{Cr}_{3} \mathrm{C}_{2}-\mathrm{Ni}$ particles reinforced coating, however, in this case oxidation was more intensive (Fig. 4 b). Also, signs of spallation of the coating's material can be observed
(Fig. 4 b), which are virtually absent in the TiC-NiMo particles reinforced coating (Fig. 4 a).

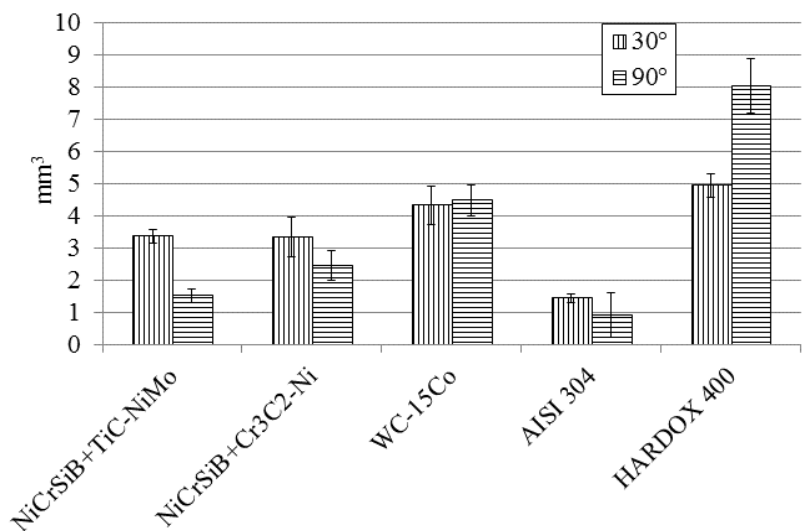

Fig. 3. High temperature erosion wear of the HVOFS coatings and the reference materials

Low-cycle surface fatigue [26] was the principle wear mechanism of both studied coatings at the normal angle of impingement (Fig. 4 c, d). Detachment of flat debris can be observed in both cases as a consequence of impacts of the abrasive particles, whereas this process is more intensive in the case of the $\mathrm{Cr}_{3} \mathrm{C}_{2}-\mathrm{Ni}$ particles reinforced coating.

The reason, why TiC-NiMo particles reinforced coating exhibited the same or lower wear in comparison with the $\mathrm{Cr}_{3} \mathrm{C}_{2}-\mathrm{Ni}$ particles reinforced one, despite the higher reinforcement content in the last, is not clear and needs further investigation. 


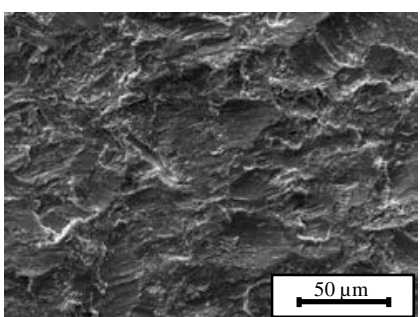

a

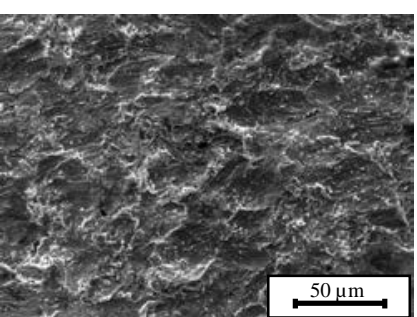

b

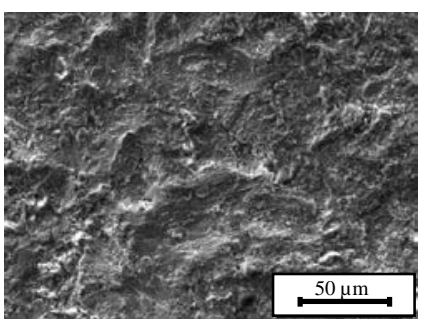

C

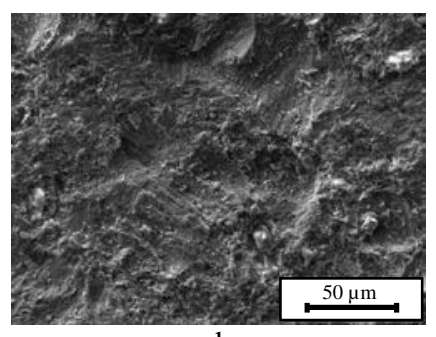

d

Fig. 4. Wear mechanisms of HVOFS coatings: a $-\mathrm{NiCrSiB}+\mathrm{TiC}-\mathrm{NiMo}, 30^{\circ}$; b $-\mathrm{NiCrSiB}+\mathrm{Cr}_{3} \mathrm{C} 2-\mathrm{Ni}, 30^{\circ}$; c $-\mathrm{NiCrSiB}+\mathrm{TiC}-\mathrm{NiMo}, 90^{\circ}$; $\mathrm{d}-\mathrm{NiCrSiB}+\mathrm{Cr}_{3} \mathrm{C}_{2}-\mathrm{Ni}, 90^{\circ}$

Currently the uneven distribution of tensile residual stresses inside the $\mathrm{NiCrSiB}+\mathrm{Cr}_{3} \mathrm{C}_{2}-\mathrm{Ni}$ coating, as shown in [27], can be suggested as a cause of its similar or higher wear in comparison with the $\mathrm{NiCrSiB}+\mathrm{TiC}-\mathrm{NiMo}$ coating. According to [28] and [29], they promote the formation of fatigue cracks and detachment of the target material during the wear process, what was observed at Fig. 4.

\section{CONCLUSIONS}

The performance of high velocity oxy-fuel sprayed coatings with matrix of $\mathrm{NiCrSiB}$ self-fluxing alloy, reinforced by $\mathrm{TiC}-\mathrm{NiMo}$ and $\mathrm{Cr}_{3} \mathrm{C}_{2}-\mathrm{Ni}$ cermet particles, at the high temperature erosion wear conditions was studied and compared to other standard wear resistant materials. The results show that at the above-mentioned conditions both studied coatings outperform the WC-15Co hardmetal and steel HARDOX 400, but exhibit higher wear than steel AISI 304. Despite the lower reinforcement content, TiC-NiMo particles reinforced coating demonstrated the same wear resistance, as the $\mathrm{Cr}_{3} \mathrm{C}_{2}-\mathrm{Ni}$ particles reinforced coating, at the low angle of impingement $\left(30^{\circ}\right)$ and better wear resistance at the normal angle of impingement $\left(90^{\circ}\right)$.

\section{Acknowledgments}

Authors thank PhD Mr Ahto Vallikivi for his help with the high temperature erosion tests and $\mathrm{PhD}$ Mr Maksim Antonov for the fruitful discussions. This research was supported in the frame of the target-financed project SF 01200091s08 "Hard coatings and surface engineering” and institutional research funding IUT19-29 "Multi-scale structured ceramic based composites for extreme applications" by Estonian Ministry of Education and Research.

\section{REFERENCES}

1. González, R., Cadenas, M., Fernández, R., Cortizo, J. L., Rodríguez, E. Wear Behaviour of Flame Sprayed NiCrBSi Coating Remelted by Flame or Laser Wear 262 (3-4) 2007: pp. 301-307. http://dx.doi.org/10.1016/j.wear.2006.05.009

2. Miguel, J. M., Guilemany, J. M., Vizcaino, S. Tribological Study of NiCrBSi Coatings Obtained by Different Processes Tribology International 36 (3) 2003: pp. 181-187. http://dx.doi.org/10.1016/S0301-679X(02)00144-5

3. Corchia, M., Delogu, P., Nenci, F. Wear Microstructural Aspects of Wear-Resistant Stellite and Colmonoy Coatings by Laser Processing Wear 119 (2) 1987: pp. 137-152. http://dx.doi.org/10.1016/0043-1648(87)90105-0
4. Li, Q., Zhang, D., Lei, T., Chen, W. Wear Comparison of Laser-Clad and Furnace-Melted Ni-Based Alloy Microstructures Surface and Coatings Technology 137 (2) 2001: pp. $122-135$.

http://dx.doi.org/10.1016/S0257-8972(00)00732-5

5. Kim, H. J., Hwang, S. Y., Lee, C. H., Juvanon, P. Wear Assessment of Wear Performance of Flame Sprayed and Fused Ni-Based Coatings Surface and Coatings Technology 172 (2) 2003: pp. 262-269. http://dx.doi.org/10.1016/S0257-8972(03)00348-7

6. Ming, Q., Lim, L. C., Chen, Z. D. Wear Laser Cladding of Nickel-Based Hardfacing Alloys Surface and Coatings Technology 106 (2) 1998: pp. 172-182. http://dx.doi.org/10.1016/S0257-8972(98)00524-6

7. Serres, N., $\quad$ Hlawka, F., $\quad$ Costil, S., $\quad$ Langlade, C., Machi, M. Corrosion Properties of In Situ Laser Remelted NiCrBSi Coatings in Comparison with Hard Chromium Coatings Journal of Materials Processing Technology 211 (1) 2011: pp. 133-140.

http://dx.doi.org/10.1016/j.jmatprotec.2010.09.005

8. Gómez-del Río, T., Garrido, M. A., Fernández, J. E., Cadenas, M., Rodríguez, J. Influence of the Deposition Techniques on the Mechanical Properties and Microstructure of NiCrBSi Coatings Journal of Materials Processing Technology $204(1-3)$ 2008: pp. 304-312. http://dx.doi.org/10.1016/j.jmatprotec.2007.11.042

9. Kulu, P. Selection of Powder Coatings for Extreme Erosion Wear Conditions Advanced Engineering Materials 4 (6) 2002: pp. $392-397$. http://dx.doi.org/10.1002/15272468(20020605)4:6<392::AID-ADEM392>3.0.CO;2-F

10. Kulu, P., Pihl, T. Selection Criteria for Wear Resistant Powder Coatings under Extreme Erosive Wear Conditions Journal of Thermal Spray Technology $11(4)$ 2002: pp. $517-522$. http://dx.doi.org/10.1361/05996302270348646

11. Wu, P., Du, H. M., Chen, X. L., Li, Z. Q., Bai, H. L., Jiang, E. Y. Influence of WC Particle Behaviour on the Wear Resistance Properties of Ni-WC Composite Coatings Wear 257 (1-2) 2004: pp. $142-147$. http://dx.doi.org/10.1016/j.wear.2003.10.019

12. Matthews, S., James, B., Hyland, M. Wear The Role of Microstructure in the High Temperature Oxidation Mechanism of $\mathrm{Cr}_{3} \mathrm{C}_{2}-\mathrm{Ni}$ Composite Coatings Corrosion Science 51 (1-2) 2009: pp. 1172-1180. http://dx.doi.org/10.1016/j.corsci.2009.02.027

13. Meng, J., Lu, J., Wang, J., Yang, S. Tribological Behaviour of TiCN-Based Cermets at Elevated Temperatures Materials Science and Engineering $A$ 418 (1) 2006: pp. 68-76.

http://dx.doi.org/10.1016/j.msea.2005.11.022 
14. Hussainova, I., Pirso, J., Antonov, M., Juhani, K. Wear High Temperature Erosion of $\mathrm{Ti}(\mathrm{Mo}) \mathrm{C}-\mathrm{Ni}$ Cermets Wear 267 (11) 2009: pp. 1849-1899. http://dx.doi.org/10.1016/j.wear.2009.03.012

15. Antonov, M., Hussainova, I., Veinthal, R., Pirso, J. Wear Effect of Temperature and Load on Three-Body Abrasion of Cermets and Steels Tribology International 46 (1) 2012: pp. $261-268$. http://dx.doi.org/10.1016/j.triboint.2011.06.029

16. Antonov, M., Hussainova, I., Kübarsepp, J., Traksmaa, R. Wear Oxidation-Abrasion of TiC-Based Cermets in SiC Medium Wear 273 (1) 2011: pp. 23-31. http://dx.doi.org/10.1016/j.wear.2011.05.005

17. Antonov, A., Hussainova, I., Pirso, J., Volobujeva, $\mathbf{O}$. Wear Assessment of Mechanically Mixed Layer Developing during High Temperature Erosion of Cermets Wear 263 (7) 2007: pp. 878-886. http://dx.doi.org/10.1016/j.wear.2006.12.035

18. Surzhenkov, A., Vallikivi, A., Mikli, V., Viljus, M., Vilgo, T., Kulu, P. Wear Resistant Self-Fluxing Alloy Based TiC-NiMo and Cr2C3-Ni Hardmetal Particles Reinforced Composite Coatings Proceedings of the $2^{\text {nd }}$ International Conference Manufacturing Engineering \& Management 2012, 5-7 December 2012, Prešov, Slovak Republic: pp. 33-36.

19. Sarjas, H., $\quad$ Goljandin, D., $\quad$ Kulu, P., $\quad$ Mikli, V., Surženkov, A., Vuoristo, P. Wear Resistant Thermal Sprayed Composite Coatings Based on Iron Self-Fluxing Alloy and Recycled Cermet Powders Materials Science (Medžiagotyra) 18 (1) 2012: pp. 34-39. http://dx.doi.org/10.5755/j01.ms.18.1.1338

20. Pirso, J., Viljus, M., Letunovitš, S., Juhani, K., Joost, R. Three-Body Abrasive Wear of Cermets Wear 271 (11) 2011: pp. $2868-2878$. http://dx.doi.org/10.1016/j.wear.2011.06.005

21. Antonov, M., Surženkov, A., $\quad$ Hussainova, I., Goljandin, D., Mikli, V. Effect of Basalt Addition on Tribological Performance of FeCrSiB HVOF Coatings Estonian Journal of Engineering 18 (3) 2012: pp. $211-220$. http://dx.doi.org/10.3176/eng.2012.3.06
22. Anan, W., Bo, Y. Wear Microstructure and Phase Constitution in NiCrSiB Alloy Produced by Laser Cladding Chinese Journal of Lasers 24 (2) 1997: pp. 169-173. http://dx.doi.org/10.1016/j.wear.2006.05.009

23. Conde, A., Zubiri, F., de Damborenea, J. Wear Cladding of Ni-Cr-Si-B Coatings a High Power Diode Laser Materials Science and Engineering A 334 (1) 2002: pp. 233-238. http://dx.doi.org/10.1016/S0921-5093(01)01808-1

24. Ting, Y., Qilin, D., Gang, D., Jianguo, Y. Influence of Ta on Microstructure and Abrasive Wear Resistance on Laser Clad $\mathrm{NiCrSiB}$ Coating Journal of Wuhan University of Technology - Materials Science Edition 28 (3) 2013: pp. 437-443. http://dx.doi.org/10.1007/s11595-013-0709-2

25. Surzhenkov, A., Antonov, M., Goljandin, D., Vilgo, T., Mikli, V., Latokartano, J., Kulu, P. Sliding Wear of TiCNiMo and Cr3C2-Ni Cermet Particles Reinforced FeCrSiB matrix HVOF sprayed coatings Estonian Journal of Engineering 19 (3) 2013: pp. 203-211. http://dx.doi.org/10.3176/eng.2013.3.03

26. Kleis, I., Kulu, P. Solid Particle Erosion. Occurrence, Prediction and Control. Springer, London, 2008: pp. 153. http://dx.doi.org/10.1007/978-1-84800-029-2

27. Ryabchikov, A., $\quad$ Lille, H., $\quad$ Reitsnik, R., Toropov, S., Surzenkov, A., Kulu, P. Investigation of Residual Stresses in Flame Sprayed Ni-Based Wear Resistant Coatings by the Hole-Drilling and X-Ray Methods Materials Science Forum 768-769 2014: pp. 144-149. http://dx.doi.org/10.4028/www.scientific.net/MSF.768769.144

28. Hussainova, I., Kübarsepp, J., Shcheglov, I. Investigation of Impact of Solid Particles against Hardmetal and Cermet Targets Tribology International 32 (6) 1999: pp. $337-344$. http://dx.doi.org/10.1016/S0301-679X(99)00073-0

29. Hussainova, I. Microstructure and Erosive Wear in Ceramic-Based Composites Wear 258 (1-4) 2005: pp. 357-365. http://dx.doi.org/10.1016/j.wear.2004.01.024 